\title{
Gender and the scissors graph of Brazilian science: from equality to invisibility
}

\author{
Roberta Arêas ${ }^{1}$ and Alice R. de P. Abreu ${ }^{2}$ and Ademir E. Santana ${ }^{3}$ and Marcia C. Barbosa ${ }^{4}$ \\ and Carlos Nobre ${ }^{5}$
}

\begin{abstract}
Women are underrepresented in science and their participation decreases as the career progresses, an international phenomenon clearly displayed in a scissors graph. This decrease is usually attributed to maternity, lower number of publications and less ability of receiving grants. Here we present a comprehensive study of the Brazilian science and technology system, covering $8,877,626$ people, and analyzing the participation of women from the undergraduate to ministerial levels. The study used different data-bases to develop relevant indicators of the participation of women, some of them over a period of 15 years. Our results suggest that the decrease of women as the career advances is due to a combination of barriers which need to be faced and eliminated to promote equity for a better science.
\end{abstract}

\section{Keywords}

Class file, $\mathrm{LT}_{\mathrm{E}} \mathrm{X} 2_{\varepsilon}, \mathrm{SAGE}$ Publications

\section{Introduction}

Although there are more female than male undergraduate and graduate students in many countries OCDE (2019), women compared with men publish less papers West et al. (2013); Huang et al. (2020) and patents Ding et al. (2006), receive lower funding Ley and Hamilton (2008) and are last or first author of publications in lower numbers West et al. (2013), particularly in fields which require a higher level of funding to build the research infrastructure, to hire staff and where there are higher publication fees Duch et al. (2012). Consequently, fewer women reach the high positions of full professors UN (2007).

The absence of women in high ranked positions has been explained as the consequence of childbearing and rearing Ceci and Williams (2011). However, these two barriers can not explain the absence of female scientists without children in the top-level position. In addition, evidence shows that women are less represented in STEM fields at all levels Hill et al. (2010); Ginter and Kahn (2006); NSF (2010) and that this might be relate to stereotypes Reuben et al. (2014) across the STEM pipeline Moss-Racusin et al. (2011); Reuben et al. (2014); Knobloch-Westerwick et al. (2013b,a); Schroeder (2013); Sheltzer and Smith (2014); Steinpreis et al. (1999); Jaschick (2014).

The bias, as any social construction, starts at early ages at primary education Bian et al. (2017) and goes up to university Emily M. Marshman et al. (2018). Looking to the career track, this bias can be observed in the hiring MossRacusin et al. (2011) process, in the way people refer to the professional using their first or surnames Atir and Ferguson (2018), in the way laboratory instructions are formulated Quinn et al. (2018) and the way scientific production is evaluated Handley et al. (2015).
The scissor effect UN (2007), the decrease of the percentage of female researchers progressively as we advance from the undergraduate to the professorship level, is present in all countries UN (2007). However, the specific numbers change from country to country.

A global and cross-disciplinary bibliometric assessment performed by Lavière and co-authors shows that the relationship between gender and research output, the extent of collaboration and the scientific impact of all articles published between 2008 and 2012 and indexed in the Thomson Reuters Web of Science databases are heterogeneous in different fields and countries KnoblochWesterwick et al. (2013a). South American and Eastern European countries have higher gender parity, even thought, women account for fewer than $30 \%$ of co-authorship, whereas men represent slightly more than $70 \%$,

That study also confirmed that fields associated with 'care' such as nursing; midwifery; speech, language and hearing; education; social work and librarianship are female dominated while military, exact sciences, engineering, robotics, aeronautics and astronautics, highenergy physics,mathematics, computer science, philosophy are male dominated fields. The same is true for Brazil Abreu et al. (2016). These differences in fields and among countries clearly indicates the relevance of cultural aspects in the construction of the bias.

\footnotetext{
${ }^{1}$ CAPES, Ministério da Educação, 70040-020, Brasília, DF, Brazil ${ }^{2}$ Universidade Federal do Rio de Janeiro, Rio de Janeiro, RJ, Brazil ${ }^{3}$ International Center of Physics, Universidade de Brasília,70910-900, Brasília, DF, Brazil

${ }^{4}$ Instituto de Física, Universidade Federal do Rio Grande do Sul, 91501 970, Porto Alegre, RS, Brazil

${ }^{5}$ Institute for Advanced Studies, Universidade de São Paulo, São Paulo, SP, Brazil

Email: roberta.silva@capes.gov.br
} 
In an attempt to measure how the participation of women in the authorship of papers changes with time and varies among world regions, Elsevier produced a global survey. They used data from Scopus, an abstract and citation database of more than 62 million documents. The authors broke the data down into 27 subject areas, and compared them across 12 countries and region for two 5-year blocks of time: 1996-2000 and 2011-15. The report included only researchers who were listed as an author on at least one publication within either of the two five-year periods. Although the proportion of women in science has grown globally, the rates were different across countries or disciplines. Brazil was the gender champion with an increase of $11 \%$ between the two periods and reaching almost $50 \%$ of authors in 2015 Mobed (2017).

The Elsevier's results suggest that gender bias might not be a problem in Brazil, since the scientific community managed not only to have the highest percentage of female scientists publishing at Scopus but also showed the larger increase in this number in the period analyzed. This result was seen by some as study reinforcing the idea that a country in which families have access to childcare, either institutionalized or through hiring private maids, can reach gender equality.

To understand if the equality observed in the Brazilian publication score at Scopus represents a real advance, we analyzed the percentage of male and female participation on scientific knowledge production in Brazil from undergraduate to the top-level positions such as ministers of education and science and technology. The aim was to verify whether equality seen at the global scenario of publication rates would also be observed at the top levels in Brazilian science and technology system. If not, this would show that the high percentage in the publication in fact hides a persistent bias where women are present at the initial stages of a scientific career but not at the top, in a clear glass ceiling effect.

\section{Results}

Figure 1 illustrates the Brazilian science and technology system. The graph is separated in three sectors: only technical, both technical and political and only political. The first group shows the percentage of male (orange) and female (purple) undergraduate and graduate students which were studying in Brazil in 2015. It also shows the percentage of male and female lecturers teaching at the undergraduate level of the universities and colleges and the percentage of male and female lecturers at graduate programs, both collected in 2015 in Brazil. In Brazil, lecturers at the graduate programs are also advisors of students and active researchers. They are ranked as adjunct, associated or full professors. At this sector of the graph women are the majority as undergraduate and graduate students, but their number decreases as lecturers and as the prestige of the position of lecturer at undergraduate and graduate courses increases.

The second sector in Figure 1 shows the percentage of man (orange) and women (purple) in positions that, even though being associated with technical skills, also require some political or networking aspects. For example, each graduate program in Brazil elects a coordinator responsible for the definition of the program's policies during a period of time which varies from two to four years. This position is occupied by a professor with a large experience as an advisor but also recognized by his/her peers as a leader. The total number of graduate programs in 2020 is 5,199 Capes (2015b). The graph illustrates the percentage of man (orange) and women (purple) as graduate program coordinators in 2020. The graph shows a decrease in the percentage of women in this position when compared with number of women working as lecturers and advisors. The difference, however, is not very large and can be explained by the fact that this position although associated somewhat with power, also implies a lot of bureaucratic work.

Another position of leadership is represented by being granted a CNPq research fellowship. This is a fellowship given to researchers with a permanent position at an university or research center usually with 10 years of $\mathrm{PhD}$ and considered of excellence. Of the 71.841 researchers that are advisors in graduate courses Capes (2015a) (one of the requirements for this research grant), 14.102 (19.6\%) $\mathrm{CNPq}$ (2015) have this type of fellowship. In order to receive such grant the researcher has to combine scientific productivity with leadership. Figure 1 shows the percentage of man (orange) and women (purple) as CNPq research fellowship recipients in 2015. The graph indicates that the percentage of women with this prestigious fellowship is not only smaller than the percentage of women working in the courses as lectures and advisors but is also smaller than the percentage of women as graduate program coordinators.

Next, we analyzed the percentage of women as $\mathrm{CNPq}$ advisory committee members. This group is responsible for deciding which researchers receive grants and in particular the research fellowship in each area of knowledge. It usually involves 10-20 people in each area of knowledge. Figure 1 shows the percentage of man (orange) and women (purple) as CNPq advisory committee members from 2005 to 2019. This position is associated with power and requires knowing and being known by the scientific community of each area. The percentage of women is smaller than the percentage of women as $\mathrm{CNPq}$ research fellowship recipients which is the universe from which $\mathrm{CNPq}$ advisory committee members are selected.

The last group in this sector of Figure 1 is represented by the coordinators of areas of knowledge at Capes. Capes is Brazil's post-graduate education agency responsible for evaluating graduate programs and giving scholarships for graduate students, grants to the better evaluated programs in the country. Each area has one coordinator. The CAPES area coordinators have more power and prestige than the $\mathrm{CNPq}$ committee members, for the decisions of the committee they chair directly impact the graduate programs. They lead the activities that confer grades to the graduate programs every four years, and if the programs are badly evaluated they will receive less scholarships to distribute to their students and might even, if they are among the lowest grades, be forbidden to confer a diploma. Figure 1 shows the percentage of man (orange) and women (purple) as Capes area of knowledge coordinators from 2011 to 2022 (the current coordinators have mandate until 2022). Numbers are related to the average over this period instead of looking at one year since the number of coordinators indicated each year is very small. The percentage of women is this position is even lower. This 


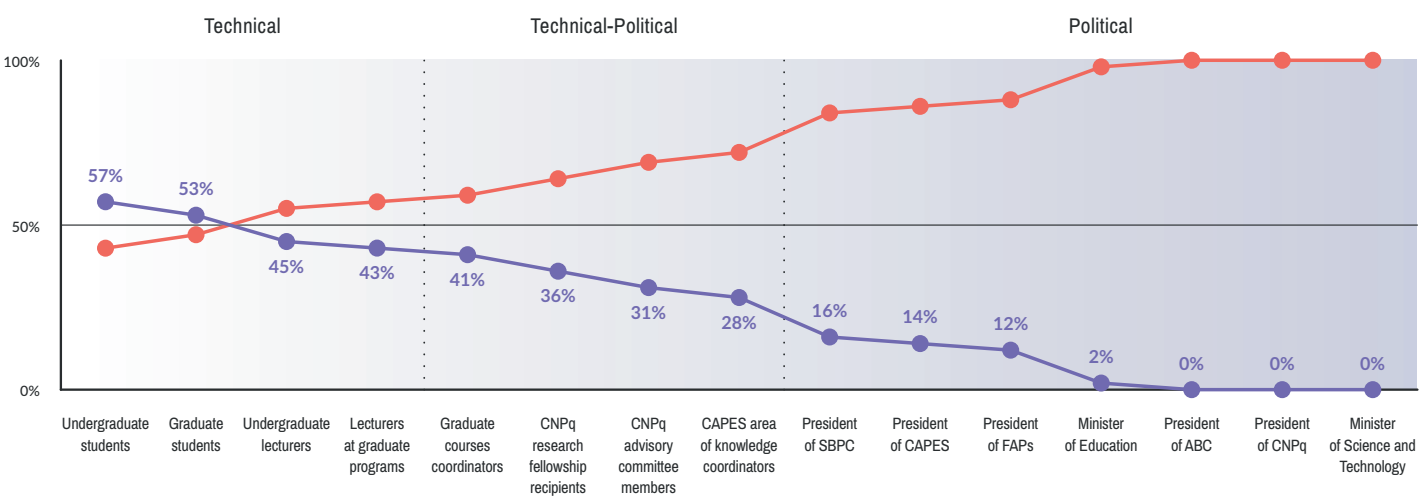

Figure 1. Brazil. Science and Technology System. Occupation of positions by sex. Detailed on the Materials and Methods section.

can be attributed to the large amount of power involved in this position.

The third sector which we defined as political involves leadership positions in academies, science funding agencies and ministries. These positions, which in several cases are occupied by scientists, have large visibility and considerable power. In this case the percentage was computed for the period in which the position existed. The Brazilian Society for the Progress of Science (SBPC) is a non profit organization involving students and professionals in science and education. The membership is by voluntary registration. It has similarities with the American Association for the Advancement of Science (AAAS) in the United States. The association has an important role in promoting and defending education, science, culture and democracy. Brazil has three large scale grant agencies: Capes which funds and evaluate the graduate programs, $\mathrm{CNPq}$ which supports individual researchers and funds large research projects and the Statelevel science funding agencies (FAP) (basically one per state) which funds research and graduate students within the State. It is interesting to notice in Figure 1 that the percentage of women as president of Capes, FAP's and CNPq decreases from $16 \%$ to $0 \%$ indicating that research areas are more prestigious than agencies which rule over educational aspects. The same can be observed when comparing SBPC to the Brazilian Academy of Sciences (ABC). The ABC members are elected by the current members and the percentage of women is much lower than the percentage of women as researchers or even researchers at the top of the career Ferrari et al. (2018). Finally, when the ministry of science and technology is compared with the ministry of education, one can see that while no women was never appointed as minister of science and technology, Brazil had one women as minister of education.

\section{Discussion}

The combination of the three sectors illustrated in Figure 1 shows that in the Brazilian science and technology system the percentage of women decreases as the position increases in power, illustrated by the well known scissors graph. This process was first identified and measured by the European Commission in data from late 1990's Commission (2003). Since then the European Commission keep track of the percentage of women in science in different countries from undergraduate to full professorship Commission (2015, 2018). This analysis, however, though quite interesting, does not reveal some of the mechanism behind the leakage of women out of science as the career advances.

The three sectors in Figure 1 suggest three mechanisms for exclusion. The first sector covers technical-only positions and shows how the career progresses from student to lecturer which requires technical skills, with a long period of training. The evidence from the literature has several explanations for the difference in numbers of men and women in this stage, from the impact of maternity in the career of women in childbearing age to the cultural norms and standards that greatly favor men, making this an institutional issue. The relatively high percentage of female authors in Brazil in the Elsevier study reflects this sector of the graph Mobed (2017) where women are still present in spite of the obstacles and challenges.

The second sector of Figure is related to activities which require technical skills but also a perception of excellence by peers and by the applicant. In general women are seen by peers or even by the students as less eminent Atir and Ferguson (2018); Araujo et al. (2017) and less deserving of eminence-related benefits and awards. In many cases, women also have a self image of being less capable Lerchenmueller et al. (2019); Emily M. Marshman 
et al. (2018). These two ingredients explain the gradual decrease in the percentage of women in this sector of the graph. Our results confirm the tendency shown in the many previous studies cited.

The third sector of Figure 1 shows the political dimensions. It involves positions filled by a single person who represents excellence, power and leadership. Women are absent of this type of positions at all sectors of human activity. In the particular case of Brazil, the absence of an affirmative action policy perpetuates this scenario.

Some say that the presence of women at the lower levels of the academic life could bring some optimism for the future generations. The high percentage of women as lectures could suggest that in some years the percentage of women as $\mathrm{CNPq}$ research fellowship researchers would be equal to the men. But strong evidence indicates that this is not the case. Analysis of 15 years of CNPq research fellowship recipients showed that the percentage of women in this category increased only 4\% Areas et al. (2019) in 15 years. Similar study for the area of physics also showed that very small changes were observed over a decade BaggioSaitovitch et al. (2015).

We can say, therefore that Figure 1 suggests that the decrease of percentage of women from undergraduate level to top research and to ministerial and political levels in science and technology is a combination of barriers which need to be faced and eliminated to promote equity for a better science Nielsen et al. (2017).

\section{Methods}

The data collected for constructing the first sector of Figure 1, called technical, refers to year 2015. The numbers of undergraduate students and lecturers were taken from the Higher Education Census, adding up to 8,027,297 and 401,299 observations, respectively Inep (2015). The data of students $(n=338,035)$ and lecturers $(n=90,307)$ of graduate program, were extracted from the Capes website Capes (2015a). That institution makes available in open access part of its current and historical databases, making it possible to find information from 2005 onward, depending on the variable of interest Capes (2015a).

The second sector of Figure 1 was constructed using two strategies. For the information regarding positions with large number of individuals we used data from one year while for positions with a smaller number of members we employed data over a decade. For example, the graduate courses coordinators in 2015 were 5,199 Capes (2015b). The number of CNPq research fellowship recipients in 2015 was $14,102 \mathrm{CNPq}$ (2015). For the CNPq advisory committee members we use the numbers from 2005, 2010, 2015 Brasil (2011) and, 2019 CNPq (2019). These years were selected because this position lasts from three to four years. The number of Capes area of knowledge coordinators from 2004 to 2018,124 coordinators, was obtained by searching within official appointment ordinance. The position lasts for three to four years.

The data for the third sector of the graph, the political positions, took into consideration all the leaders since the creation of each organization. The information was obtained using both the websites of the organizations and by requesting the information to the different institutions using the Law of Information Access. The total number of leaders for each organization is: for the State Foundations of Support for Research, $n=104$, Brazilian Society for the Progress of Science - SBPC, $n=19$, area coordination for the Improvement of Higher Education Personnel - CAPES, $\mathrm{n}=$ 21, Brazilian Academy of Sciences - ABC, $n=16$, National Council for Scientific and Technological Development CNPq, $\mathrm{n}=27$, Ministry of Education - MEC, $\mathrm{n}=62$ and, Ministry of Science and Technology. $n=22$.

\section{References}

Abreu ARP, Oliveira MCFA, Vieira JM and Marcondes GS (2016) Présence des femmes dans les sciences et la technologie au brésil. In: Guimarães NA, Maruani M and Sorj B (eds.) Genre, race, classe. Travailler en France et au Brésil. Paris: L'Harmattan. Collection Logiques Sociales, pp. 179-194.

Araujo EB, Araujo NAM, Moreira AA, Herrmann HJ and Andrade Jr JS (2017) Gender differences in scientific collaborations: Women sre more egalitarian than men. Plos One 12(5): e0176791.

Areas R, Barbosa MC and Santana AE (2019) Teorema de emmy nother, 100 anos: Alegoria da misoginia em ciência. Revista Brasileira de Ensino de Fisica 41(4): e2019001.

Atir S and Ferguson MJ (2018) How gender determines the way we speak about professionals. Proceedings of the National Academy of Sciences of the United States of America 115(28): 7278-7283.

Baggio-Saitovitch E, Barbosa MC, Funchal RZ and de Pinho AE S T R Santana (2015) Gender equity in the brazilian physics community at the present time. In: AIP Conference Proceedings, volume 41. p. 060007.

Bian L, Leslie SJL and Cimpian A (2017) Gender stereotypes about intellectual ability emerge early and influence children's interests. Science 355: 389-391.

Brasil (2011) Lei de acesso à informação (access to information law) 12,527. Brazilian Law which gives access to government data.

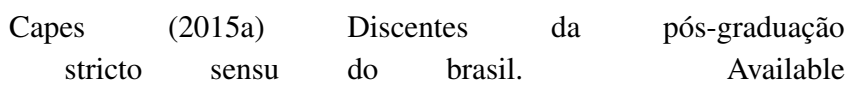
at:=https://dadosabertos.capes.gov.br/dataset/discentes-dapos-graduacao-stricto-sensu-do-brasil [Accessed in February 7, 2020].

Capes (2015b) Plataforma sucupira. Available at:=https://sucupira.capes.gov.br/sucupira [Accessed in February 7, 2020].

Ceci SJ and Williams WM (2011) Understanding current causes of women's underrepresentation in science. Proceedings of the National Academy of Sciences of the United States of America 108(8): 3157-3162.

CNPq (2015) Séries históricas até 2015. Available at:=http://www.cnpq.br/series-historicas [Accessed in February 7, 2020].

CNPq (2019) Membros dos comitês. Available at:=http://cnpq.br/membros-dos-comites/ [Accessed in February 7, 2020].

Commission E (2003) Third european report on science and technology indicators. Available at:=https://ec.europa.eu/research/press/2003/pdf/indicators2003/reist_2003.p 
[Accessed in February 7, 2020].

Commission E (2015) She figures 2015. Available at:=https://data.europa.eu/euodp/en/data/dataset/she-figures2015-gender-in-research-and-innovation [Accessed in February 7, 2020].

Commission E (2018) She figures 2018. Available at:=https://publications.europa.eu/en/publicationdetail/-/publication/9540ffa1-4478-11e9-a8ed01aa75ed71a1/language-en [Accessed in February 7, 2020].

Ding WW, Murray T and Stuart TE (2006) Gender differences in patenting in the academic life sciences. Science 313(5787): 665-667.

Duch J, Xiao HTZ, Sales-Pardo M, Raidcchi F, Otis S, Woodruff TK and Amaral AN (2012) The possible role of resource requirements and academic career-choice risk on gender differences in publication rate and impactthe role of gender in scholarly authorship. PLOS ONE 7(12): e51332.

Emily M Marshman EM, Kalender ZY, Nokes-Malach T, Schunn C and Singh C (2018) Female students with a's have similar physics self-efficacy as male students with c's in introductory courses: A cause for alarm? Physical Review Physics Education Research 14(17): 020123-020140.

Ferrari NC, Martell R, Okido DH, Romanzini G, Magnan V, Barbosa MC and Brito C (2018) Geographic and gender diversity in the brazilian academy of sciences. Annals of the Brazilian Academy of Sciences 90(2): 2243-2552.

Ginter DK and Kahn S (2006) Does science promote women? evidence from academia 1973-2001. Available at:=www.nber.org/papers/w12691 [Accessed in January 25, 2020].

Handley IM, Brown ER, Moss-Racusin CA and Smith JL (2015) Quality of evidence revealing subtle gender biases in science is in the eye of the beholder. Proceedings of the National Academy of Sciences of the United States of America 112(43): 13201 - 13206.

Hill C, Corbett C and Rose AS (2010) Why so few? women in science, technology, engineering, and mathematics.

Huang J, Gates AJ, Sinatra R and Barabasi LA (2020) Historical comparison of gender inequality in scientific careers across countries and disciplines. Proceedings of the National Academy of Sciences of the United States of America .

Inep (2015) Sinopses estatísticas da educação superior - graduação. Available at:=http://inep.gov.br/sinopses-estatisticas-daeducacao-superior [Accessed in February 7, 2020].

Jaschick S (2014) Productivity or sexism? inside higher education. Available at:=www.insidehighered.com/news/2014/08/18/study-raisesquestions-about-why-women-are-less-likely-men-earn-tenureresearch [Accessed in January 25, 2020].

Knobloch-Westerwick S, Glynn CJ and Huge M (2013a) Bibliometrics: Global gender disparities in science. Nature 504(7479): $211-213$

Knobloch-Westerwick S, Glynn CJ and Huge M (2013b) The maltida effect in science communication: An experiment on gender bias in publication quality perceptions and collaboration interest. Science Communication 35(5): 603 -625.

Lerchenmueller MJ, Sorenson O and Jena AB (2019) Gender differences in how scientists present the importance of their research: observational study. The British Medical Journal 367 16573. Available at:https://www.bmj.com/content/ bmj/367/bmj.16573.full.pdf [Accessed in February 7, 2020].

Ley TJ and Hamilton BH (2008) The gender gap in nih grant applications. Science 322(5907): 1472-1474.

Mobed R (2017) Gender in the global research landscape.

Moss-Racusin CA, Davidio JF, Brescoll VL, Graham M and Handelsman J (2011) Science faculty's subtle gender biases favor male students. Proceedings of the National Academy of Sciences of the United States of America 109(41): 1647416479.

Nielsen MW, Alegria S, Börjeson L, Etzkowitz H, Falk-Krzesinski HJ, Joshi A, Leahey E, Smith-Doerr L, Woolley AW and Schiebinger L (2017) Gender diversity leads to better science. Proceedings of the National Academy of Sciences of the United States of America 114(8): 1740 - 1742.

NSF (2010) Women, minorities, and persons with disabilities in science and engineering (national center for science and engineering statistics. Available at:=www.nsf.gov/statistics/2015/nsf15311/ [Accessed in January 25, 2020].

OCDE (2019) Education at a glance 2012. Available at:=https://www.oecd.org/education/highlights.pdf [Accessed in February 7, 2020].

Quinn KN, McGill KL, Kelley MM, Smith EM and Holmes NG (2018) Who does what now? how physics lab instruction impacts student behaviors. In: Physics Education Research Conference 2018 Part of the PER Conference series. p. xx.

Reuben E, Sapienza P and Zingales L (2014) How stereotypes impair women's careers in science. Proceedings of the National Academy of Sciences of the United States of America 111(12): $4403-4408$.

Schroeder Jea (2013) Fewer invited talks by women in evolutionary biology symposia. Journal of Evolutionary Biology 26(9): $2063-2069$.

Sheltzer JM and Smith JC (2014) Elite male faculty in the life sciences employ fewer women. Proceedings of the National Academy of Sciences of the United States of America 111(28): 10107 - 10112

Steinpreis RE, Anders KA and Ritzke D (1999) The impact of gender on the review of the curricula vitae of job applicants and tenure candidates: A national empirical study. Sex Roles 41(7/8): 509 - 528 .

UN (2007) United nations educational, scientific and cultural organization. science, technology and gender: An international report. Available at:=http://www.unesco.org/new/en/naturalsciences/science-technology/sti-policy/global-focus/genderissues/unesco-report-on-science-technology-and-gender-2007/ [Accessed in January 25, 2020].

West JD, Jacquet J, King M, Correll SJ and Bergstrom CT (2013) The role of gender in scholarly authorship. PLOs ONE 8(7): e66212. 